\title{
Evaluating ELF Students' Speaking Skill at Tertiary Level
}

\author{
Dr. Fadiel Mohammed Musa
}

\section{Assistant Professor}

\section{Department of English Language}

\section{Nahda College}

\section{Omdurman, Khartoum, Sudan}

\section{fadielmoosa@yahoo.com}

\begin{abstract}
:
This study was conducted at a Sudanese university in 2021 at the end of the semester to find out the areas caused problems of speech production. The research paper seeks to answer the question: What area/s of speaking is problematic to students? Fortysix undergraduate students in first year, who were majored in the English programme involved in the test. The total population was hundred students. Analytic rubrics were used for collecting data. Tuan (2014, p. 2) states that analytic rubric“... accesses the examinee's specific strengths and weaknesses and identifies the particular components of speaking discourse that an examinee needs to develop". Five explicit criteria were used to test participants; i.e.: grammar, vocabulary, pronunciation, cohesion and fluency. The test was conducted by two instructors who gave appropriate marks under each of five rubrics (Table 1 below). The test contents comprised some pictures and topics to speak about. Bar charts were utilized to compare and measure marks obtained by students in analytic rubrics, where each rubric was measured individually. The results revealed that students were weak in all five areas (grammar, vocabulary, punctuation, cohesion and fluency).The highest marks were gained in pronunciation, count $25 \%$, while the lowest marks were obtained in vocabulary, $15 \%$ from the total mark allocated
\end{abstract}


for this item. The results conveyed that, this group of participants was weak in all aspects that needed for speech production compared with their level ( $2^{\text {nd }}$ year undergraduates).

Keywords: Analytic Rubrics, Assessment, Coherence, Holistic Rubrics, Fluency

I. Introduction

Speaking represents a major skill in any instructions of English in the globe. Hence, EFL courses give priority to speaking activities. In addition, most of the learners keep this aim on the top of their learning purposes. From the researcher's experience, approximately all English learners of General or English for Specific Purposes, regardless of their majors or ages, express their need for being skillful speakers. Unfortunately, they always speak out their anxiety about being crippled and prevented from fulfilling this desire. Therefore; learners as well as lecturers need feedback on what holds L2 learners from being fluent speakers.

Aim of study

This research paper is a reaction due to lack of speech fluency mentioned above. It aims at identifying areas of weakness that stand as an obstacle which hinder learners to be fluent English speakers. Hereby, the aim of this research paper is to find an answer to the question: Which area/s of speaking is problematic to students?

\section{Literature Review}

New trends of English language instructions

Speaking is an essential part in conveying message in communication. As mentioned above, speaking is the main goal of teaching/ learning English in Sudan. O'Brien (2003, p. 5) points out that the English syllabus (Nile Course) in 1980s aims at; “..... involving communication, interaction and interpretation ..."

Krashen claims that "We acquire language when we understand what people tell us and what we read....there is no need for deliberate memorization." 
Difficulty of speaking assessment

There are mainly three methods to assess language skills: indirect (e. g.: multiple choice tests), semidirect, where "prerecorded questions or tasks typically under laboratory conditions" (Ginther 2017, p. 3), and direct measurement. To assess the participants this research follows the direct method; i.e.: facetoface assessment. Isaac (2016, p. 10) states that "facetoface interactions tend to be more appealing to testtakers and may result in more authentic assessments".

Generally, direct assessment of speaking entails a number of factors on which a test is based. Test designers should consider three things: test takers, information examiners want to know about the examinee and adequate method of testing. A number of educators have expressed their views about difficulties in conducting speaking assessment. Knight (1992, p. 2), states that lack of time, difficulty of designing speaking tasks, and what criteria to use are the major difficulties in testing speaking. Gómez and Cortès (2013, p. 78) find out that lack of time and big number of students, lack of background of how to assess speaking are among the obstacles of conducting speaking examination. The researcher as an examiner noticed that testers faced real difficulty while performing this examination because of time consuming. For instance, in this test there were forty students each one was given ten minutes, so the test took 400 minutes to complete (more than six hours).

Analytic and holistic rubrics

To be more specific in describing speech hindrances, either analytic or holistic rubrics are used to investigate the problem. Brookhart (2013, p. 7) quoted in Shatrova et al (2017) defines rubric as “...a coherent set of criteria for students' work that includes descriptions of levels of performance quality on the criteria". California County Superintendents Educational Services Association (CCSESA) describes rubric as “...a scoring scale used to assess student performance a long a taskspecific set of criteria." 
Holistic rubric enables researchers to have an overall summary of the learners' performance and production. Holistic rubric concentrates on what students are able to do and what they cannot. Luoma (2009, p. 61) mentions that 'The Finnish National Certificate Scale' describes the holistic scales of speakers, ascending from 6 to 1 . In scale 6 , the speakers speak fluently with few foreign accent. In scale 5, the learner can speak fluently without frequent obvious need to search for an expression. In the fourth category the learner is able to talk about and describe sights, sounds and experiences. Scale 3, speech may be quite slow but there are few unnatural pauses. In No. 2, category learners in their simplest situation, their pronunciation may deviate clearly from the target language norm. Finally, the last type in this category, the speakers are able to ask and reply to simple questions dealing with immediate everyday needs. Speakers can make use of simple polite forms with slow communication.

Ibid (2009, p. 62) notes that holistic criteria “....are not practical for diagnosing strengths and weaknesses in individual learners' performances."

On the other hand, analytic rubrics measure factors and criteria in details separately. One example of analytic rubric is detecting students' performance and competence in grammar, vocabulary use, or pronunciation, with a separate score for each test item in an oral examination. This research paper adapts the analytic scale. One of the known scales in this area is 'The Test of Spoken English (TSE) scale'. The (TSE) has 3 to 5 criteria, where the examinee gets score for each. TSE describes in first criteria, speakers are almost always effective communicators. Whereas in the second criteria, communication is generally effective. In the third criteria, communication is somewhat effective. In criteria four, communication is generally not effective. Luoma $(2009$, p. 68) states that "The advantages of analytic scales include the detailed guidance that they give to raters, and the rich information that they provide on specific strengths and weaknesses in examinee performances." 
Speaking and pronunciation

Clear word utterance and articulation are important for comprehensibility. The raters in this study checked students' pronunciation of short vowels, long vowels, diphthongs, sound and nonsound consonants, stress, intonation, etc...in extensive speaking. Speaking and Grammar

In speech, the speakers usually are not abiding by grammar boundary as in writing. So, grammar in speaking is evaluated within the context, e.g. discussions. Musa (2018, p. 9) states that "Grammar in context is taught through speaking, e.g., dialogues and discussions of real situations.”Similarly, Ounis (2017, p. 3), points out that “...communicative approach concentrates on developing the learner's ability to communicate effectively and views grammar study as just one of the vehicles that can be used to promote communicative competence."

Coherence

Order and organization of ideas are necessary for speech act to be intelligible. Though features of spoken language are different from those written ones, but there are similarities between them. For example, both demand connected and grouped ideas; i.e.: coherence. Hoffman et al (2020, p. 3)states that “...a speaker must identify the topic under discussion, generate a series of statements relevant to this subject and monitor their speech as the discourse unfolds to ensure that they remain ontopic."

\section{Fluency}

Fluency denotes the mastering and ability to use language clearly. In common, fluency means command of general aspects of language performance. In this research paper, fluency means: ability to use lexica, semantics, intonation and grammar to communicate a topic. 


\section{Method}

Participants

The respondents involved in this study were second year undergraduate students who majored in English language. The syllabus content for second year is composed of five subjects: English Grammar in Use, Listening \& Speaking, Paragraph Writing, Introduction to Linguistics, and Introduction to Literature.

To measure and find out about this group of students' speaking fluency and accuracy a test was used. Two examiners were involved in testing the students. The test was based on the students' background; i.e., what the students had already studied. The examiners used five analytic rubrics: pronunciation, grammar, vocabulary, cohesion, and fluency; each with separate score (five marks each).To reduce bias each of the examiners evaluated examinees without knowing his other colleague's evaluation. That is to say; each examiner had a separate list of the students' names for entering marks. Then the two examiners immediately compare the examinee's oral test when s/he finished.

Data Collection

Role of examinees (Students) and examiners (teachers)

The examination consisted of a number of tasks, such as: settings, scenes, descriptive and argumentative topics. To defuse any tension the examinees were first given warmup. The aim of the examination was to involve the examinees in extensive interaction with the examiners.

Here was the procedure that testers followed to collect data.

1 Examiners checked the format of the speaking examination carefully.

2 At the beginning the students introduced themselves.

3 Examiners sometimes intervened to keep speech process on.

4 Testers gave the examinees enough time to speak, exactly ten minutes each. 
5 Marks were entered using the initials in table 1 below.

6 Then, the examiners displayed a number of photographs using digital projector. 7 Test takers chose a photo and spoke about what they see. 8 Then the examinees related the events in the photo to their personal life, e.g. talked about their childhood.

Table1 Rating points (adopted from Rahmawati\&Ertin(2014, p. 7)

\begin{tabular}{|l|l|l|}
\hline Initial & Criteria & Score \\
\hline E & Excellent & 5 points \\
\hline VG & Very Good & 4 points \\
\hline G & Good & 3 points \\
\hline S & Satisfactory & 2 points \\
\hline P & Poor & 1 point \\
\hline
\end{tabular}

For more specification, the above table was used. For example, if a student used wide range of vocabulary, he got $E$ 'Excellent'. Or the examiner would write $P$ 'Poor' if examinee showed narrow and repeated vocabulary.

IV. Results, Findings and Discussions

The bar chart below illustrates the performance of the participants in the speaking test in the five selected speaking components: grammar, vocabulary, pronunciation, cohesion and fluency. An overview of the chart shows poor and unsatisfactory achievement in this speaking course since the general results show marked decline in all five tested speaking components. 
Table 2 students' score on the five analytic rubrics (2020 2021)

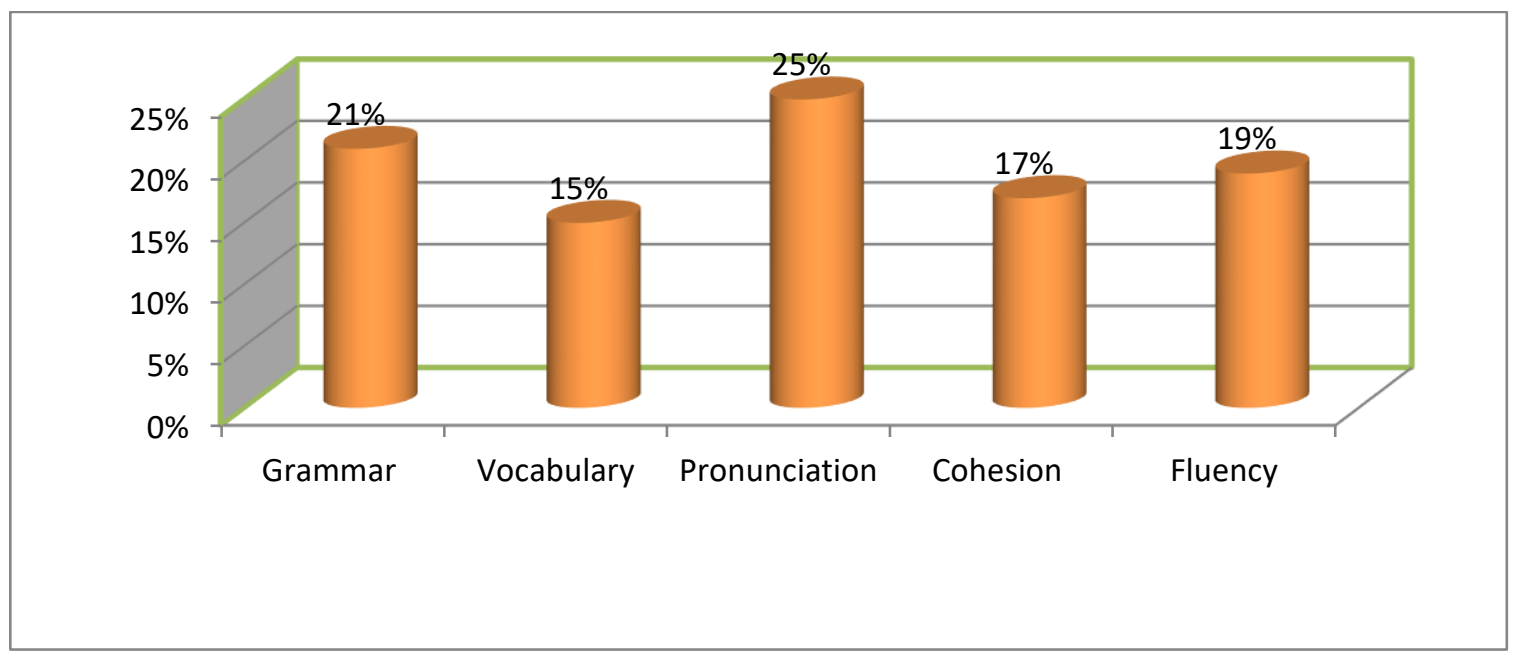

There is fluctuation in the total result rates. For example in grammar only $21 \%$ of the examinees could pass, while the lowest marks were gained in vocabulary, count $15 \%$. In all five tested areas the highest proportion students got was $25 \%$; i.e.: pronunciation. By looking at 'cohesion' and 'fluency' the examinees scored low percentage. It is worth noting that the participants had limited ability of building connected speech as well as low ability of fluency in which they scored only $17 \%$ and $19 \%$ respectively.

The findings indicate that all of the components necessary for speaking are problematic for this group, where there is a big gap between the students' standard of spoken language and what is expected from them in this level (second year undergraduates).

Recommendations and suggestions for improvements

There is a need for reshaping the output of speaking of the students who are specialized in English language. Therefore, the researcher recommends that speaking skill should be of high priority for the undergraduate students.

The writer recommends and suggests the followings:

It is advisable to assess speaking continuously throughout the academic year; i.e. continuous assessment rather than during examinations only. This serves two aims: to avoid lack of time and to remedy weakness - if any before the end of the semester. 
From the researcher point of view, there should be a review of syllabus as well as reviewing the aim of English Language instructions at tertiary level.

To help building students' capacity in acquiring L2, the four skills of English language should be of equal importance.

There should be a change of syllabus with emphasis on speaking skill, especially in first and second year undergraduates, to cope with the new trends of foreign language teaching/learning. 


\section{References}

Ginther, 2017, Assessment of Speaking, 2013 Blackwell Publishing Ltd. Published 2013 by Blackwell Publishing Ltd. DOI: 10.1002/9781405198431.wbeal0052

Hoffman, P., 2020, Going off the Rails: Impaired coherence in the speech of patients with semantic control deficits, Centre for Cognitive Ageing and Cognitive Epidemiology, Department of Psychology, University of Edinburgh

Isaacs, T., (2016), Assessing Speaking, In D. Tsagari\& J. Banerjee (Eds.),Handbook of second language assessment (pp. 131-146). Berlin: DeGruyter Mouton

Isabel, M., and Cortes, A., 2013, Assessing Speaking Skill, English and French Program, University of Marino

Knight, B.,2016,Assessing Speaking skills:A workshop for teacher development,ELT Journal, July 1992 DOI: 10.1093/elt/46.3.294

Musa, F., 2018, Grammar in Context and Isolation: The Effect on the Two Teaching Methods on Students' Writing Skill, unpublished research Submitted for the Requirements of the Degree of PhD in English

O’Brien, J., English Language in Sudanese Schools - a way forward Delivered at Humanities and Educational Studies Conference University of Khartoum, Sudan February 25 28,203

Luoma, S., 2014, Assessing Speaking, Cambridge University Press 2004

Shatrova, Z., et al. 2017, English Speaking Assessment, International Journal of English Language Teaching, Vol.5, No.3, pp.2740, April 2017

Rahmawati, Y., and Ertin, 2014, Developing Assessment for Speaking, IJEE, Vol. 1, No. 2, 2014 
Ounis, A., The Assessment of Speaking Skills at the Tertiary Level, International Journal of English Linguistics; Vol. 7, No. 4; 2017 ISSN1923869XEISSN19238703, Published by Canadian Center of Science and Education

Tuan, L., 2012, Teaching and Assessing Speaking Performance through Analytic Scoring Approach, Theory and Practice in Language Studies, Vol. 2, No. 4, pp. 673679, April 2012 